\title{
NARRATIVA DE VIDA DE MARIA FERNANDES DE QUEIROGA (IRMÃ ANA, OSF): MEMÓRIA, HISTÓRIA E IDENTIDADE DOCENTE
}

\author{
NARRATIVA DE VIDA DE MARIA FERNANDES DE QUEIROGA (HERMANA ANA, \\ OSF): MEMORIA, HISTORIA E IDENTIDAD DOCENTE
}

\section{LIFE NARRATIVE OF MARIA FERNANDES DE QUEIROGA (SISTER ANA, OSF): MEMORY, HISTORY AND TEACHING IDENTITY}

\author{
Iolanda de Sousa BARRETO ${ }^{1}$ \\ Charliton José dos Santos MACHADO² \\ Maria Lúcia da Silva NUNES ${ }^{3}$
}

RESUMO: Este artigo objetiva delinear o percurso de construção da identidade docente da educadora e religiosa Maria Fernandes de Queiroga (Irmã Ana, OSF), que tem atuado por mais de cinco décadas na formação de professoras/es, no Colégio Normal Francisca Mendes (CNFM), em Catolé do Rocha/PB, a partir de uma leitura de sua trajetória de vida e atuação educativa. Pautado nas ideias difundidas pela Nova História Cultural, nos modos investigativos da (auto)biografia, da micro história e da história oral, desenvolve uma abordagem histórica das fontes constituídas por entrevistas de história oral, cadernos e escritos da educadora, documentos referentes ao CNFM, entre outros. Irmã Ana vem edificando sua identidade docente no acolhimento, na reflexão e na adaptação das influências dos grupos - referências às quais esteve ligada ao longo de sua vida: a família, a congregação religiosa, as instituições formativas e o(s) lugar(es) de atuação profissional.

PALAVRAS-CHAVE: Formação de professoras/es. Docência. Identidade.

RESUMEN: Este artículo tiene como objetivo esbozar el camino de construcción de la identidad docente de la educadora y religiosa María Fernandes de Queiroga (Hermana Ana, OSF), que trabaja desde hace más de cinco décadas en la formación de docentes del Colégio Normal Francisca Mendes (CNFM), en Catolé do Rocha/PB, a partir de una lectura de su trayectoria de vida y desempeño educativo. A partir de las ideas difundidas por la Nueva Historia Cultural, en las modalidades investigativas de (auto)biografia, microhistoria e historia oral, se desarrolla un acercamiento histórico de las fuentes constituidas por entrevistas de historia oral, cuadernos y escritos del educador, documentos relacionados con el CNFM, entre otros. Hermana Ana ha ido construyendo su identidad docente acogiendo, reflejando y adaptando las influencias de los grupos de referencia a los que ha estado

\footnotetext{
${ }^{1}$ Secretaria da Educação e Cultura (SEDEC), João Pessoa - PB - Brasil. Professora do Departamento de Educação Básica. Doutorado em Educação (UFPB). ORCID: https://orcid.org/0000-0002-2909-6240. E-mail: iolandasbarreto@gmail.com

${ }^{2}$ Universidade Federal da Paraíba (UFPB), João Pessoa - PB - Brasil. Professor Titular do Departamento de Metodologia da Educação. Doutorado em Educação (UFRN). Bolsista de Produtividade em Pesquisa do CNPq Nível 1D. ORCID: https://orcid.org/0000-0002-4768-8725. E-mail: charlitonlara@yahoo.com.br

${ }^{3}$ Universidade Federal da Paraíba (UFPB), João Pessoa - PB - Brasil. Professora do Departamento de Metodologia da Educação. Doutorado em Educação (UFRN). ORCID: https://orcid.org/0000-0001-9316-1281. E-mail:mlsnunesml@gmail.com
} 
vinculada a lo largo de su vida: la familia, la congregación religiosa, las instituciones de formación y los lugares de rendimiento profesional.

PALABRAS CLAVE: Formación del profesorado. Enseñanza. Identidad.

ABSTRACT: This article aims to outline the path of construction of the teaching identity of the educator and religious Maria Fernandes de Queiroga (Sister Ana, OSF), who has worked for more than five decades in teacher training, at Colégio Normal Francisca Mendes $(C N F M)$, in Catolé do Rocha/PB, from a reading of her life trajectory and educational performance. Based on the ideas spread by the New Cultural History, in the investigative modes of (auto)biography, of micro history and oral history, develops a historical approach of the sources constituted by oral history interviews, notebooks and writings of the educator, documents relating to CNFM, among others. Sister Ana has been building her teaching identity in welcoming, in the reflection and adaptation of the influences of the reference groups to which she has been linked troughout her life: the family, the religious congregation, the training institutions and the place(s) of professional practice.

KEYWORDS: Teacher education. Teaching. Identity.

\section{Introdução}

O presente artigo ${ }^{4}$ objetiva delinear o percurso de construção da identidade docente da educadora e religiosa Maria Fernandes de Queiroga (Irmã Ana, OSF), que tem atuado por mais de cinco décadas na formação de professoras/es, no Colégio Normal Francisca Mendes (CNFM), no Alto Sertão da Paraíba, a partir de uma leitura de sua trajetória de vida e atuação educativa. Para tal, considera-se o seu empenho na formação de professoras/es, por meio de sua atuação como professora e coordenadora do Curso Normal do CNFM, assim como o seu esforço contínuo para manter o funcionamento do colégio outrora e nos dias atuais, desenvolvendo atividades docentes e relacionadas à sua administração, constituindo-se, ao longo deste tempo, como guardiã de valores confessionais e saberes educacionais apreendidos por meio da convivência com diversos grupos-referências, sobretudo as Irmãs Franciscanas de Dillingen, podendo a educadora ainda ser descrita como guardiã do próprio colégio e de tudo o que ele representa.

A reconstituição da trajetória de vida da educadora, englobando sua formação e atuação profissional, deu-se a partir da análise de fontes orais, com destaque para as suas próprias narrativas de memória, mas também por meio de fontes escritas e imagéticas por ela

${ }^{4}$ Este texto é um recorte da pesquisa de doutoramento intitulada A GUARDIÃ: um retrato histórico e (auto) biográfico de Maria Fernandes de Queiroga (Irmã Ana, OSF) - 1949 a 2019, realizada entre os anos de 2016 e 2019, a partir do Programa de Pós-Graduação em Educação da Universidade Federal da Paraíba. Para saber mais, consultar Barreto (2019). 
disponibilizadas, como cadernos, fotografias, textos (auto)biográficos e documentos oficiais do colégio, além de livros sobre a cidade de Catolé do Rocha, sobre a história das Irmãs Franciscanas de Dillingen, e ainda trabalhos acadêmicos sobre o CNFM.

Cabe aqui considerar a complexidade que se impõe ao estudo em pauta, haja vista a impossibilidade de se condensar uma vida em uma narrativa historiográfica, independentemente do número de páginas que possa conter, pois do contrário, corre-se o risco de cair na armadilha de uma "ilusão biográfica", a qual seria, conforme de Bourdieu (1986, p. 69): "tratar a vida como uma história, isto é, como o relato coerente de uma sequência de acontecimentos com significado e direção." Uma história de vida, portanto, não se apreende, não se finda em uma narrativa, e o pesquisador deve assumir uma postura coerente ao dedicar-se à operação historiográfica. Neste sentido, também alerta Oliveira (2011, p. 66):

[...] Como é ilusória a figura de um sujeito do conhecimento neutro, que observa 'de fora' os fenômenos na suposição de apreendê-los por inteiro para, ao final, construir sobre eles uma imagem definitiva. Determinar completamente o objeto simbolizaria o poder arbitrário do sujeito do conhecimento, mas também a morte do objeto, daí a ilusão que recobre tais práticas.

$\mathrm{Na}$ atualidade, sob influência das disciplinas como a Sociologia e a Antropologia, há um destacado interesse por abordagens e metodologias que enfocam histórias de vidas, identidade e memória, nas quais a (auto)biografia aponta não somente a capacidade de apresentar a trajetória de uma vida singular, mas de possibilitar uma percepção mais acurada dos processos coletivos. É um trabalho minucioso de compreensão e interpretação, em que a partir das fontes e dos métodos utilizados se vai revelando nuances da realidade estudada. Por isso, para Le Goff uma biografia parte inicialmente da vida de um indivíduo e a "legitimidade do gênero histórico passa pelo respeito a esse objetivo: a apresentação e a explicação de uma vida individual na história. Mas uma história iluminada pelas novas concepções da historiografia" (LE GOFF, 1989, p. 49).

A investigação neste trabalho desencadeada enveredou pelas dimensões da pessoa, da prática e da profissão do professor, comungando com o pensamento de Nóvoa (1992, p. 15), de que: "O professor é a pessoa; e uma parte importante da pessoa é o professor". Nesse sentido, refletir sobre a ação educativa de Irmã Ana ou sobre a de qualquer outro profissional da docência impõe considerar as especificidades inerentes à sua identidade pessoal, que, por conseguinte, particularizam o seu fazer educativo.

\section{O sujeito da pesquisa}


Décima filha do casal João Adelino de Queiroga e Ana Fernandes de Queiroga, Irmã Ana nasce como Maria Fernandes de Queiroga, em 03 de fevereiro de 1936, na cidade de Antenor Navarro (atualmente denominada de São João do Rio do Peixe), sertão paraibano. No ano de 1941 desloca-se com a família para Catolé do Rocha, onde o pai assumiria um emprego federal nos Correios e Telégrafos. Nesse período esse pequeno município era palco de duas inusitadas ocorrências: a fundação da Escola Normal Dona Francisca Henriques Mendes e a chegada das cinco irmãs franciscanas de Dillingen, religiosas alemãs que se tornariam as responsáveis pelo funcionamento do colégio e pela formação de muitas jovens catoleenses e do seu entorno geográfico, que a partir dele se fizeram professoras.

Concluídas as experiências do ensino primário e do Exame de Admissão, em 1949, aos 13 anos, Irmã Ana ingressa no Curso Normal Regional do Colégio Dona Francisca Henriques Mendes, período que assim descreve: "Que alegria! Foram quatro anos onde podíamos saborear o néctar dos conhecimentos de vários professores, de modo especial das Irmãs Franciscanas de Dillingen, fundadoras dessa instituição de ensino" (QUEIROGA, 2016).

Desde sua fundação, o CNFM funcionou com o curso primário e o Curso Normal, nos primeiros anos denominado "Normal Livre", modalidade pouco abordada na historiografia da educação brasileira, mas da qual é possível inferir que a designação "livre" se daria devido à autonomia concedida pela legislação brasileira aos estados para que elaborassem as suas próprias matrizes curriculares, entre outras prerrogativas (SOUSA, 2012, p. 59).

A partir de 1946, o Curso Normal livre é substituído pelo Curso Normal Regional, sendo a primeira turma de regentes de ensino diplomada no ano de 1949, conforme o Livro de Atas das Sessões Magnas de Formatura. Esse curso foi instituído de acordo com a Lei Orgânica do Ensino Normal, posta em vigor pelo Decreto-Lei n. ${ }^{\circ}$ 8.530, de 2 de janeiro de 1946. Os dois cursos, Normal Livre e Normal Regional têm, portanto, especificidades. Para Oliveira (2013, p. 144):

A adjetivação "livre" do primeiro apontaria para o princípio da liberdade das democracias modernas, que, no campo da educação, toma corpo na defesa da livre iniciativa de particulares do ensino, e no papel indeclinável do Estado para normatizar e controlar essa atividade, na esfera pública e privada. Por sua vez, a adjetivação "regional", do segundo, estaria significando a circunscrita validade do título expedido pelo Normal Regional, principalmente quando se considera a maior amplitude do Normal $2^{\circ}$. Ciclo e o direito dele advindo de pleitear acesso à Universidade, pela via do Vestibular. 
Em meados do século XX, Irmã Ana estava inserida nesse contexto de euforia professoral que movimentava a pacata localidade de Catolé do Rocha. Jovens normalistas mergulhavam em campos de conhecimento diversos, assim como numa densa gama de atividades socioculturais, como realça Oliveira (2013, p. 148-149):

Nos anos cinquenta, o Normal Regional do Francisca Mendes desenvolvia sua formação com disciplinas de duração variada: Religião; Português; Desenho e Caligrafia; Canto Orfeônico; Educação Física e Jogos (todas em 4 anos); Matemática; Trabalhos Manuais (3 anos); Botânica; Física e Química (2 anos); Geografia Geral; Geografia do Brasil; H. Geral; H. do Brasil; Psicologia e Pedagogia; Higiene; Didática e Prática de Ensino (1 ano).

Irmã Ana afirma que aos 14 anos já se sentia vocacionada à vida religiosa, contudo, guardava para si seu desejo, pois a mãe não gostava da ideia. Contudo, provavelmente a convivência direta com as irmãs fundadoras do CNFM tenha marcado profundamente o espírito da jovem, de forma que não desiste do seu intento e, aos 22 anos, após receber a licença dos pais, ingressa como candidata aos votos religiosos, no convento de Areia.

É possível afirmar que, desde o ano de 1949, Irmã Ana começa, de fato, a construir o seu vínculo com o CNFM, que perdura até os dias atuais, quando continua participando ativamente da rotina do colégio, das decisões pedagógicas e administrativas, tendo ocupado até o ano de 2017 o cargo de diretora-geral da instituição.

\section{A construção de um colégio ou a construção de uma história}

Nos anos finais da década de 1930, vislumbrava-se em Catolé do Rocha as bases para a construção de um colégio, o qual se configurava para os seus idealizadores e para a gente de posses local, assim como para políticos, intelectuais e autoridades religiosas, como um projeto redentorista, capaz de trazer prosperidade e civilidade à região.

Muitos depoimentos registrados no Livro de Impressões sobre o Projecto do Collegio D. Francisca Henriques Mendes ${ }^{5}$ reforçam esses valores, concebendo o desenvolvimento intelectual e moral para as gerações futuras, como se constata nos escritos. De acordo com Antonio Botto de Menezes, então deputado federal paraibano: “A obra, que o Cel Antonio Mendes Ribeiro [...] vai edificar, sob a doce invocação do nome de sua genitora, no município de Catolé do Rocha, destina-se ao preparo das gerações do amanhã. É semente nova e fecunda reservada ao futuro [...]" (IMPRESSÕES, 1937-1938).

E com o então vigário local, o Pe. Joaquim de Assis Ferreira:

${ }^{5}$ Documento sob a guarda do CNFM. Manuscrito não paginado, datado de 1937. Mantida a ortografia da época. 
O Colégio "D. Francisca Henriques Mendes", dádiva preciosa do Coronel Antonio Mendes Ribeiro à Diocese de Cajazeiras e à cidade de Catolé do Rocha, berço de sua genitora que dá nome ao Educandário, representa para o Sertão da Paraíba uma esmola de luz que se não esquece [...] (IMPRESSÕES, 1937-1938).

O projeto da construção do Colégio Dona Francisca Henriques Mendes surgiu em uma época de escassos recursos voltados para a educação da população, marcada pelo fechamento de escolas subsidiadas pelo poder público, o qual, inclusive, com a Constituição de 1937, passa a incentivar diretamente a iniciativa privada, e minimiza o dever do Estado com a educação. Nesse sentido, o texto propunha que a arte, a ciência e o ensino fossem livres à iniciativa individual e à associação ou reunião de pessoas públicas e particulares.

Como a abertura de escolas confessionais era de interesse da Igreja, a partir de uma rede de relações locais, envolvendo lideranças religiosas, políticas e econômicas, foram lançados os alicerces do edifício que mudaria e marcaria, definitivamente, a paisagem do pequeno município paraibano e a vida de parcela da comunidade local, considerando que os menos abastados ficavam de fora desse projeto. Cabe aqui destacar o conceito de redes de sociabilidade, que para Martins (2007, p. 432) seriam "a representação das interações contínuas das diferentes estratégias individuais". Quais seriam, no entanto, os principais personagens dessa rede local?

Em primeiro lugar, o capitalista bem-sucedido do ramo imobiliário da capital paraibana, o coronel Antônio Mendes Ribeiro, desejoso de edificar uma obra com a qual pudesse honrar e imortalizar a memória de sua genitora, a catoleense Francisca Henriques Mendes. Além dele, o vigário local, Padre Joaquim de Assis, que, em sintonia com os ideais católicos de evangelizar por meio da educação, e atentando às carências percebidas na região, indica ao empreendedor a construção de um educandário para moças como a obra ideal ao seu propósito. E ainda, o então prefeito Natanael Maia Filho, membro de uma família da elite política catoleense e paraibana, que faz a doação de terreno público para a construção do prédio escolar.

Além da cultura política familista destacada como predominante no município, nesse contexto, a cultura política nacionalista também é percebida nos comportamentos concretos de indivíduos notórios ou comuns, afinal a construção de um sentimento nacionalista está em ebulição em todo o país. Nas palavras de Pécault (1990, p. 15): “organizar a nação, esta é a tarefa urgente, uma tarefa que cabe às elites. [...] forjar um povo também é traçar uma cultura capaz de assegurar a sua unidade". 
A história da fundação do colégio ganha um capítulo diferencial com a chegada das cinco irmãs franciscanas de Dillingen que emigram para o Brasil no ano de 1939, juntamente a outras irmãs de sua congregação, instalando-se nas cidades de Cabo Frio, no Rio de Janeiro, e Areia, na Paraíba. Em virtude das perseguições às ordens católicas na Alemanha e da necessidade de elencar dirigentes para instituições confessionais no Brasil, autoridades eclesiásticas brasileiras fazem o convite, que é aceito pelas estrangeiras. As cinco freiras alemãs que chegam para assumir o funcionamento da então Escola Dona Francisca Henriques Mendes instalam-se inicialmente em Areia (PB) e, convocadas pelo bispo de Cajazeiras (PB), Dom João da Mata Amaral, rumam para Catolé do Rocha, sendo acolhidas por autoridades locais que, inclusive, se incubem de sua acomodação até que a construção do prédio do colégio seja concluída e elas possam lá se instalar, o que acontece no início de 1940. Segundo Sendra (2007, p. 166): "Enquanto o Colégio estava ainda sendo construído, o Curso Primário funcionou numa das casas cedidas pelo Coronel Sérgio Maia. E o Curso Normal Livre ficou instalado na parte concluída do Colégio".

Nesse contexto, tem início a história de muitas professoras formadas no CNFM, que puderam desenvolver a prática docente a partir dos ensinamentos das cinco irmãs fundadoras ou das coirmãs brasileiras que a elas se seguiram e também abraçaram esse mister, a formação de professoras.

\section{A constituição de uma identidade}

A construção da identidade, apesar de ela ser, aparentemente, uma instância individual, processa-se, continuamente, em relação a um coletivo. É, segundo Pollak (1992, p. 200), "um fenômeno que se produz em referência aos outros, em referência aos critérios de aceitabilidade, de admissibilidade, de credibilidade, e que se faz por meio da negociação direta com os outros".

Nesse ponto cabe refletir sobre as influências que constituíram Irmã Ana enquanto sujeito, enquanto educadora e enquanto freira, ou seja, sobre a constituição de sua identidade individual e coletiva. Destaca-se, nesse processo de construção identitária, a ação dos gruposreferência (GABRIEL, 2011), sobretudo a família, a Igreja e a sua congregação religiosa, entre outros, com realce para a convivência com as irmãs franciscanas fundadoras do CNFM.

Em sua narrativa Irmã Ana enfatiza que a convivência com as mestras, as madres fundadoras do CNFM, e as demais professoras do Curso Normal daquele colégio, despertoulhe o gosto pelo magistério. Entende-se, pois, que a construção de sua identidade docente se 
dá, sobretudo, a partir dessa convivência, considerando-se também os próprios interesses coletivos da época, afinal a maioria das jovens catoleenses almejava seguir a carreira do magistério, enaltecida pelas autoridades políticas e eclesiásticas locais como ação intelectual e, ainda, libertadora e missionária, como se pode perceber em trecho do discurso do Pe. Américo Sérgio Maia, orador oficial da sétima turma de professoras do Colégio Dona Francisca Henriques Mendes:

Educar não quer somente dizer acumular conhecimentos, mas fazer chegar ao desenvolvimento e à plena eficiência todas as faculdades que se acham em germinação na criança. A jovem professora deve-se fazer portadora da luz de Jesus Cristo, como catequista, como apóstola da ação católica (LIVRO, 1942-1959, p. 19).

A identidade individual constrói-se em comunhão com a identidade social. Assim, o sujeito, bebendo em diversas fontes, vai se constituindo a si mesmo, criando percepções e fazendo escolhas, muitas vezes por influência direta de outros sujeitos ou grupos, o que, num movimento contínuo, aos poucos pode ir reconstruindo-se, afirmando-se ou transformando-se, conforme o próprio indivíduo se perceba em relação a si mesmo e aos outros. Segundo Pollak, na construção da identidade, há a presença de três elementos essenciais:

Há a unidade física, ou seja, o sentimento de ter fronteiras físicas, no caso do corpo da pessoa, ou fronteiras de pertencimento ao grupo, no caso de um coletivo; há a continuidade dentro do tempo, no sentido físico da palavra, mas também no sentido moral e psicológico; finalmente, há o sentimento de coerência, ou seja, de que os diferentes elementos que formam um indivíduo são efetivamente unificados (POLLAK, 1992, p. 200, grifo nosso).

No que diz respeito à identidade de Irmã Ana, é possível perceber a unificação desses elementos, processo solidificado ao longo das suas mais de oito décadas de vida. Sem dúvida, nesse movimento, ela recebe e acolhe influências de diversos grupos com os quais se integra ou convive, no entanto demonstra certa autonomia em suas escolhas, considerando-se as opções disponíveis à figura feminina em seu espaço-tempo social e de formação. Conclui o Curso Normal e decide-se pela docência. De início, surgem-lhe outras opções de trabalho, mas as rejeita por não estarem relacionadas à área escolhida. Decide-se pela vida religiosa consagrada aos 14 anos de idade, mas enfrenta a objeção materna. Mesmo assim, continua firme em seu propósito e aos 22 anos consegue entrar para o convento como candidata, recebendo a autorização dos pais.

Sempre que indagada sobre sua escolha vocacional, Irmã Ana enfatiza o desejo pessoal e, mais do que isso, considera ter recebido um chamado divino. Em suas palavras: 
"Deus é que me atraiu, não é? Deus me atraiu". Pondera, contudo, que o ambiente que a cercava lhe era favorável à escolha, pois os pais sempre foram muito piedosos, sendo a igreja quase que um complemento do lar. Revela que admirava as práticas piedosas das irmãs, mas deixa claro que não houve interferência delas em sua decisão pela vida consagrada, conforme relata:

[...] eu tomei a minha decisão com quatorze anos e ninguém tirou mais da minha cabeça, só que eu nunca disse a ninguém. Depois eu terminei aqui no colégio e eu estudava datilografia com Irmã Engelsindis e uma vez, ela conversando e meu irmão já estava no seminário, e ela me perguntou se eu não queria ser religiosa. Foi a única pergunta. Ai eu não tinha mais como esconder, eu já tinha dezessete anos, foi a primeira vez que eu disse a Irmã Engelsindis. Aí depois ela passou para minha irmã e aí chegou lá em casa e foi aquele chororô lá de casa. Mas eu só cheguei a entrar no convento com vinte e dois anos porque meus pais não deixaram (QUEIROGA, 2016a).

Ao concluir o Normal Regional no CNFM, alimenta o desejo de lá lecionar, o que, no entanto, não se concretiza de imediato. Assim, passa a trabalhar no comércio, tarefa que não lhe agradava. Surge a oportunidade de substituir uma professora do colégio que estava gestante, sua então vizinha Maria Celi Fixina, mas, como o cargo era temporário, retorna ao comércio, em 1954, para ajudar um irmão que acabara de instalar uma loja de roupas masculinas. Nesse meio tempo, recebe outros convites de trabalho, mas resolve recusá-los por não se identificar com os ofícios. Talvez a família tenha tentado integrá-la em outras ocupações a fim de que pudesse realmente confirmar ou não a sua intenção para a vida consagrada, afinal, à época, o caminho para o casamento e a constituição de uma nova família era considerado não somente o natural para a mulher, mas também o desejado, haja vista a força da representação dessa instituição no cenário social.

Não que tenha ocorrido um determinismo, ou seja, que Irmã Ana estivesse predeterminada a ser o que é, mas naquela época a mulher, assim como o homem, tinha o seu lugar definido dentro da divisão sexual. Afinal, há muito tempo: "cada sexo tem sua função, seus papéis, suas tarefas, seus espaços, seu lugar quase predeterminado, em seus detalhes" (PERROT, 1992, p. 178).

Em sua narrativa percebe-se a importância que os pais davam ao casamento, o que, contudo, não era o desejado por todos os filhos. Assim, cabe inferir que, com as possibilidades que tem, cada indivíduo constrói-se, a princípio, a partir de caminhos e descaminhos, escolhas e renúncias, bem como de seu próprio livre-arbítrio. No que se refere à Irmã Ana, não parece ter havido um conflito de identidade em sua história de vida; ao contrário, elementos apontam para uma tomada de consciência, para um processo de 
identificação, para um encontrar-se a si própria no mundo, enquanto mulher, enquanto educadora e enquanto freira, a partir do que ela recebe e de como interage em seu contexto sócio-histórico.

Em 1962, Irmã Ana, então pertencendo à Congregação das Irmãs Franciscanas de Dillingen na Província do Nordeste, a Província de Nossa Senhora Medianeira das Graças, retorna de um intenso período de preparação em Areia e instala-se no CNFM, assumindo as tarefas religiosas e educacionais a ela confiadas, passando, em pouco tempo, a lecionar Matemática no ginásio, Desenho no ginásio e no Curso Normal, Higiene e Puericultura no $4^{\circ}$ Normal Regional e Ensino Religioso no $3^{\circ}$ ano primário. Ela afirma que não foi fácil assumir todo esse trabalho, pois a sua formação era para o curso primário, mas destaca que sempre teve o apoio e a orientação das irmãs alemãs e que o fato de gostar do que fazia foi fundamental para o seu êxito e a sua realização profissional. Paralelamente à realização dos trabalhos, não deixava também de buscar aprimoramentos, participando de cursos voltados para a área da Educação, iniciativa hoje chamada de "formação continuada" ou "permanente".

Como havia carência de professores para ensinar as diferentes matérias do currículo ginasial na Paraíba, alguns cursos eram ofertados com a finalidade de capacitar professores e conceder-lhes o registro de ensino da matéria cursada, o que se dava por meio da aprovação em exames de suficiência. ${ }^{6}$ No ano de 1965, com o intento de conseguir o registro de professora de Matemática para o $1^{\mathrm{o}}$ ciclo ginasial, Irmã Ana realiza, na capital paraibana, o $1^{\mathrm{o}}$ Curso de Preparação Intensiva de Professores de $1^{\circ}$ Ciclo, promovido pela Faculdade de Filosofia, Ciências e Letras da UFPB, em convênio com a Diretoria de Ensino Secundário, do Ministério da Educação e Cultura. $O$ curso teve a duração de um semestre letivo, de $1^{\circ}$ de julho a $1^{\circ}$ de dezembro do ano de 1965 . Como já lecionava Matemática, com o término do curso e o recebimento do registro, passou a ensinar a disciplina com a certificação oficial.

Paralelamente a esse curso, participa de outro realizado no Instituto de Educação da Paraíba, com duração de uma semana e dirigido a professores do Curso Normal. O curso foi ministrado por professoras de Belo Horizonte e, na ocasião, Irmã Ana participou em companhia de Irmã Eleonore Brumm, uma das irmãs alemãs responsáveis pela administração do CNFM. Daí surgiu a oportunidade de realizar um curso mais aprofundado em Belo Horizonte, no ano de 1966, oferecido pelo Instituto Nacional de Estudos Pedagógicos, por meio do Centro Regional de Pesquisas Educacionais João Pinheiro/Divisão de

${ }^{6} \mathrm{O}$ exame de suficiência constituiu-se como medida emergencial adotada pelo Ministério da Educação e Saúde (MÊS), por meio do Decreto-Lei n. ${ }^{\circ} 8.777$, de 22 de janeiro de 1946 (BRASIL, 1946), com vistas a minimizar a defasagem de professores para atuarem no ensino secundário, haja vista que o número de faculdades de Filosofia, especializadas na formação de professores para esse nível de ensino, era insuficiente no país. 
Aperfeiçoamento de Professores (CRE-DAP), curso que sempre é referenciado por ela como um momento importante de sua formação profissional, conferindo-lhe, de acordo com suas palavras, um aprofundamento teórico-prático "similar ao de uma especialização".

Dedica-se, de maio a dezembro do ano de 1966, ao curso de aperfeiçoamento de professores ministrado em Belo Horizonte, cursando diversas disciplinas, com cargas horárias variando de 12 a 137 horas, num total de 847 horas-aula, englobando estudos em Didática da Matemática (disciplina com maior carga horária), Didática de Estudos Sociais, Didática das Ciências Naturais, Prática de Ensino na Escola Normal, Currículo e Supervisão na Escola Primária e Psicologia Educacional, entre outras áreas do conhecimento. Nessa experiência, Irmã Ana pôde interagir com os professores ministrantes das diversas disciplinas e com os professores participantes, que, assim como ela, estavam em busca de aprofundamento teórico para atuar em seus espaços profissionais.

O curso realizado em Belo Horizonte - MG capacitou-lhe para ministrar todas as Didáticas do Curso Normal do CNFM, assim como a Prática de Ensino e, ainda, o trabalho de orientação pedagógica que realizou neste colégio e no $8^{\circ}$ Centro de Supervisão (órgão vinculado à Secretaria de Educação do Estado da Paraíba) de Catolé do Rocha, como coordenadora das supervisoras de ensino, de 1977 a 1980. Neste trabalho de orientação pedagógica, enfatiza a parceria com Gercina de Freitas Lopes, professora a quem confiou a regência da Didática da Matemática no curso pedagógico do CNFM e que também participava do processo de avaliação das professorandas no estágio supervisionado da instituição.

O processo de construção de uma identidade profissional, segundo Moita (1995, p. 115):

É uma construção que tem uma dimensão espácio-temporal, atravessa a vida profissional desde a fase da opção pela profissão até à reforma, passando pelo tempo concreto de formação inicial e pelos diferentes espaços institucionais onde a profissão se desenrola. É constituída sobre saberes científicos e pedagógicos como sobre referências de ordem ética e deontológica. É uma construção que tem a marca das experiências feitas, das opções tomadas, das práticas desenvolvidas, das continuidades e descontinuidades, quer ao nível das representações, quer ao nível do trabalho concreto.

Nesse sentido, percebe-se que Irmã Ana paulatinamente vai dando corpo à sua práxis educativa, assumindo novas funções profissionais, delegando atribuições a outros colaboradores do mister de formação professoral e educacional, desenvolvido não somente em nível do CNFM, mas, inclusive, na rede de ensino estadual. Lança mão dos 
conhecimentos adquiridos nos espaços de formação ao mesmo tempo que vai em busca de novos saberes e de atualização profissional.

Do curso de Belo Horizonte, a educadora guarda, além do certificado, um caderno de quase 300 páginas manuscritas em frente e verso (QUEIROGA, 1966). A primeira página, condizendo com a sua identidade religiosa, traz uma prece voltada para o início do trabalho; nas demais, constam anotações sobre as unidades de ensino das várias disciplinas cursadas, englobando aspectos históricos e teóricos concernentes a cada área, metodologias de ensino, avaliação, preparo do professor, prontidão da criança para a aprendizagem, planos de aula e exercícios de fixação, entre outros apontamentos, inclusive, realçando a importância do diálogo entre as disciplinas, conceito atualmente chamado de "interdisciplinaridade" e de grande destaque nas teorias pedagógicas contemporâneas.

No ano de 1971, Irmã Ana é convidada para lecionar Matemática em turmas do $1^{\circ}$ e do $2^{\circ}$ Científico no Colégio Estadual Obdúlia Dantas. Contratada pelo estado, desempenha essa função até 1973, quando passa no vestibular da UFPB para cursar Pedagogia. Consegue que o seu contrato com o estado seja transferido para a Escola Estadual Sesquicentenário, localizada em João Pessoa, onde leciona Matemática por quatro anos.

Fazer Pedagogia foi o coroamento para o exercício de sua prática profissional. $\mathrm{Na}$ academia, segundo ela, teve excelentes professores e havia bastante socialização de conhecimentos a partir de trabalhos em grupos. Recorda que, quando chegou o momento de realizar atividades sobre a temática "unidades de trabalho", tinha o diferencial de já ter exercitado o conteúdo durante o curso realizado em Belo Horizonte, tendo sido para ela bem mais fácil do que para as demais colegas da graduação passar por essa etapa do programa, tornando-se, inclusive, coordenadora do grupo.

Durante a formação no curso de Pedagogia, Irmã Ana nunca abandonou o trabalho no CNFM, nem mesmo mentalmente, segundo ela. A orientação das professoras do Curso Normal era prioridade para a educadora, assim em todas as oportunidades se fazia presente no colégio. Quando havia aulas ou dias livres, seguia para Catolé do Rocha a fim de ministrar aulas no Curso Normal e realizar orientações junto às professoras em formação.

Irmã Eleonore Brumm, nessa época, era a responsável pela administração do CNFM, mas também era provincial, ou seja, havia sido eleita para coordenar todas as irmãs da província, no caso, a Província do Nordeste, Província Franciscana de Nossa Senhora Medianeira das Graças. Dividia-se, assim, entre as demandas do colégio e as obrigações da ordem religiosa, mas contava com a ajuda direta de Irmã Ana, sobretudo como colaboradora 
dos trabalhos de orientação das professoras, mas também como professora de várias Didáticas do Curso Normal.

Ao concluir o curso de Pedagogia na UFPB, em dezembro de 1976, com habilitação para Administração Escolar, Supervisão Escolar e Prática Pedagógica, recebe o registro conferido pela Inspetoria Técnica de Ensino da Paraíba para ensinar Psicologia da Educação, Sociologia da Educação e Didática Geral. Em janeiro de 1977, Irmã Eleonore Brumm entrega à Irmã Ana a administração do CNFM e desloca-se definitivamente para Areia, após 38 anos de efetivo trabalho naquela instituição de ensino.

A partir dos relatos da educadora, evidencia-se o empenho de Eleonore Brumm em preparar Irmã Ana para dar continuidade à linha de trabalho educacional e confessional estabelecida pelo grupo das pioneiras irmãs alemãs, as franciscanas de Dillingen, do qual fazia parte. Fica claro também a dedicação de Irmã Ana a esse mister, trabalhando com afinco, recebendo os aconselhamentos e pondo em prática os ensinamentos advindos dessa convivência. Os processos de construção da identidade profissional de Irmã Ana como professora, supervisora, coordenadora e administradora escolar, bem como os processos de construção de sua identidade pessoal como mulher, religiosa e ainda como guardiã do CNFM, têm a marca de muitos grupos, mas também de indivíduos em especial.

Com relação à Irmã Ana, é possível afirmar que todo esse tempo de dedicação à educação e ao CNFM revela-se fecundo, no sentido de que adquiriu experiências e aprendizados, ao mesmo tempo em que colaborou com a formação de muitos professores, os quais foram, por sua curiosidade própria, mas também a partir dos conhecimentos adquiridos em interação, construindo novos saberes inerentes à prática educativa.

De 1962 a 2015, período que Irmã Ana atuou no Curso Normal do CNFM, de acordo com dados de matrículas obtidos na secretaria do colégio, foram alunos(as) ${ }^{7}$ ou receberam orientações da educadora em tela 1.345 professoras/es formadas/os na instituição. Foram 53 anos de dedicação à formação professoral que geraram um resultado significativo, como se comprova no número, que ultrapassa a casa do milhar.

Analisando-se as fontes é possível afirmar que muitos foram os conhecimentos pedagógicos transmitidos por essa educadora. Desde a elaboração das unidades de ensino e o cuidado com a coerência entre conteúdos programáticos, objetivos, metodologias e avaliação da aprendizagem até a preparação dos recursos didáticos de forma que o ensino pudesse se mostrar mais atrativo e eficiente. A desenvoltura na ministração das aulas no período do

${ }^{7}$ De acordo com dados coletados no CNFM, seis professores do sexo masculino concluíram o Curso Normal no CNFM ao longo de sua história. 
estágio supervisionado era outro ponto que merecia atenção e orientação de Irmã Ana e das demais professoras responsáveis pela condução dessa etapa.

Assumir a educação foi para Irmã Ana mais do que assumir uma profissão, foi tomar uma missão, conforme os preceitos de sua ordem religiosa - e talvez por isso ela ainda não tenha se permitido parar. É visível o seu empenho científico, a busca contínua por conhecimentos que subsidiassem a sua ação, podendo-se refletir sobre ela a partir da asserção de Freire (2007, p. 22): "se o meu compromisso é realmente com o homem concreto, com a causa de sua humanização, de sua libertação, não posso por isso mesmo prescindir da ciência, nem da tecnologia, com as quais me vou instrumentando para melhor lutar por esta causa".

A formação de professores e a formação cristã sempre foram prioridade para ela, como se percebe nos seus relatos, nos depoimentos de outros sujeitos ou na análise das fontes. Isso não significa afirmar que ela nunca tenha cometido erros e talvez tenha até deixado alguma marca negativa em alguns dos que passaram por ela. Ela mesma, numa perspectiva autoavaliativa, pertinente a todo/a educador/a, assim se percebe: "[...] ninguém é tão sábio que não tenha erros, eu penso. Eu não posso dizer que faço tudo muito bom, nós temos nossas falhas, são falhas humanas" (QUEIROGA, 2017).

Desde a sua fundação, no ano de 1939, o CNFM ofereceu a formação para o magistério: inicialmente com o curso denominado "Normal Livre", em seguida com o Normal Regional, ambos correspondentes ao que hoje se convenciona chamar de "ensino fundamental". Em 1965, com a implantação do Curso Pedagógico, a formação passa a corresponder ao ensino de segundo grau e, a partir da LDB n. ${ }^{\circ}$ 9.394/96, com a mudança de nomenclatura dos níveis de ensino, configurou-se como Curso Normal em nível médio, com a exigência de quatro anos de formação profissional. A nova matriz curricular do curso passou a exigir uma carga horária de 4.560 horas/aula, com a obrigatoriedade de uma regência de 320 horas/aula. Para isto, as professoras titulares do ensino fundamental do colégio teriam de ceder muito tempo de sua sala de aula. Comprometida com a missão de formar professores, e sabedora da importância social dessa formação, Irmã Ana esforçou-se para manter o Curso Normal, adequando-o às novas exigências. Para tanto, concebeu, em 2005, o projeto "Flor de Mandacaru", que visava resolver o problema da regência para as estagiárias do Curso Normal, possibilitando-lhes a experiência profissional necessária e, ainda, abrir as portas do colégio para acolher crianças oriundas das classes menos favorecidas.

Assim, foram abertas turmas no colégio para atender as crianças incluídas no perfil descrito, cujos pais eram informados no ato da matrícula sobre as especificidades do projeto. De acordo com a proposta, as estagiárias seriam acompanhadas por uma professora titular em 
cada sala, que daria apoio didático e psicológico às cursistas. A elaboração das unidades de ensino era acompanhada pela orientadora pedagógica, responsável, ainda, por observar a execução das aulas, realizando uma avaliação crítica que favorecesse a atuação docente das estagiárias. O projeto Flor de Mandacaru funcionou de 2005 a 2013, tendo sido encerrado, segundo Irmã Ana, devido à falta de adesão de novas candidatas ao Curso Normal e, ainda, aos seus altos custos de execução.

Esgotadas as tentativas, Irmã Ana constata, por fim, a falta de êxito em manter o funcionamento do curso no colégio devido à baixa procura e ao desinteresse das alunas. A narrativa expressa um desencanto, afinal, a formação para o magistério está impressa em sua própria identidade, e isso não mais acontece com outros sujeitos. Segundo Irmã Ana, há um movimento de desprestígio, e consequente declínio, do magistério na conjuntura atual, e isso tem consequências: num futuro próximo, haverá uma carência de professores de ensino fundamental, os chamados polivalentes. ${ }^{8}$

Do tempo áureo do Curso Normal, Irmã Ana guarda muitas lembranças. Recorda também, com saudosismo, de sua atuação com as turmas lotadas de alunos, das várias implementações feitas ao longo do tempo, de como gostava de lecionar... Suas memórias trazem à tona um passado esgotado no presente, mas que compõe a sua história, a história do colégio, a história dos muitos professores formados naquela escola.

\section{Considerações finais}

O caminho percorrido neste trabalho enveredou pelas reentrâncias da constituição identitária e prosseguiu em seu objetivo de compreender a trajetória de vida de Irmã Ana enquanto pessoa e enquanto profissional da docência e, a partir dessa trajetória, adentrar no conhecimento de sua práxis educativa, problematizando-a e contextualizando-a aos elementos que se dão a ver nesse processo; quer seja a influência do contexto sócio-histórico do seu tempo de formação; quer seja a influência dos grupos-referência de sua vida e de sua prática (família, Igreja, grupos estudantis e religiosos, Irmãs Franciscanas de Dillingen, entre outros); quer seja a relação de imbricamento com o CNFM; quer seja ainda o seu processo próprio de busca e de autoformação.

Algumas questões colocam-se em face do ponto-chave de como uma pessoa se

\footnotetext{
${ }^{8}$ Denominação que se refere aos professores dos anos iniciais do ensino fundamental, responsáveis por ministrar as disciplinas básicas do currículo escolar: Língua Portuguesa, Matemática, História, Geografia e Ciências. Embora a expressão "professor polivalente, não mais apareça na legislação brasileira atual, os docentes desse seguimento de ensino, na prática, continuam atuando como polivalentes" (PIMENTA et al., 2017, p. 17).
} 
transforma em professor/a ou de como a sua ação pedagógica é influenciada pelas características próprias assumidas no decurso de cada vida particular. As respostas, no entanto, não chegam sem se considerar, ou melhor, sem se analisar os processos identitários de cada sujeito feito professor/a.

Irmã Ana, como educadora e como freira, traz consigo e repercute em suas ações as marcas da educação recebida no seio familiar, nos anos de escolarização vivenciados, sobretudo no CNFM, e na convivência direta com as irmãs franciscanas de Dillingen, fundadoras da instituição educativa. Responsável pela formação de um número de professores que ultrapassa a casa do milhar, desenvolveu uma práxis que teve e tem um alcance para além das fronteiras de seu lugar de atuação, haja vista que muitos(as) alunos(as) formados(as) no CNFM migraram ou ainda migram para diferentes cidades da Paraíba e até de outros estados, levando consigo os valores e aprendizados construídos nessa experiência educativa e disseminando-os entre outros sujeitos sociais com os quais interagem.

\section{REFERÊNCIAS}

BARRETO, I. S. A Guardiã: um retrato histórico e (auto)biográfico de Maria Fernandes de Queiroga (Irmã Ana OSF) - 1949 a 2019. 2019. 349 f. Tese (Doutorado em Educação) Universidade Federal da Paraíba, João Pessoa, PB, 2019.

BOURDIEU, P. L'illusion biographique. Actes de la Recherche em Sciences Sociales, Paris, v. $62 / 63$, p. $69-72$, jun. 1986.

BRASIL. Decreto-lei n. 8.777, de 22 de janeiro de 1946. Dispõe sobre o registro definitivo de professores de ensino secundário no Ministério da Educação e Saúde, Brasília, DF, 24 jan. 1946. Disponível em: https://www2.camara.leg.br/legin/fed/declei/1940-1949/decreto-lei8777-22-janeiro-1946-416416-publicacaooriginal-1-pe.html. Acesso em: 16 out. 2020.

FREIRE, P. Educação e mudança. 30. ed. Rio de Janeiro, RJ: Paz e Terra, 2007.

\section{GABRIEL, G. L. Narrativa autobiográfica como prática de formação continuada e de}

atualização de si: os grupos-referência e o grupo reflexivo na mediação da constituição identitária do docente. 1. ed. Curitiba, PR: CRV, 2011.

IMPRESSÕES sobre o Projecto do Collegio D. Francisca Henriques Mendes a ser construído por seu filho Cel. Antônio Mendes Ribeiro e doado à Diocese de Cajazeiras (1937-1938). Documento manuscrito sob a guarda do Colégio Normal Francisca Mendes.

LE GOFF, J. Comment écrire une biographie historique aujourd'hui. Le Débat, Paris, n. 54, p. 48-53, 1989.

LIVRO de Atas das Sessões Magnas de Formatura de Regentes de Ensino Primário da Escola Normal Regional D. Francisca Mendes. Documento manuscrito, sob a guarda do Colégio 
Normal Francisca Mendes, Catolé do Rocha (PB); constituído de 50 páginas numeradas, datado de 1942 e contendo os registros das sessões de 1942 a 1959. Documento manuscrito. Colégio Normal Francisca Mendes, Catolé do Rocha (PB), 1942 a 1959.

MARTINS, M. F. Os tempos de mudança: elites, poder e redes familiares, séculos XVIII e XIX. In: FRAGOSO, J. L. R.; ALMEIDA, C. M. C.; SAMPAIO, A. C. J. (Org.).

Conquistadores e negociantes: história das elites no Antigo Regime nos Trópicos. América Lusa, Séculos XVI a XVII. Rio de Janeiro, RJ: Civilização Brasileira, 2007. p. 403-434.

MOITA, M. C. Percursos de formação e de trans-formação. In: NÓVOA, A. (Org.) Vidas de professores. 2. ed. Porto, Portugal: Porto Editora, 1995. p. 111-140.

NÓVOA, A. Os professores e as histórias da sua vida. In: NÓVOA, A. (Org.). Vidas de professores. Trad. Maria dos Anjos Caseiro e Manoel Figueiredo Ferreira. Porto, Portugal: Porto Editora, 1992, p. 11-30.

OLIVEIRA, M. L. B. Um colégio no alto da cidade. In: MELO, A. L. G. et al. (Org.). Catolé do Rocha em muitas lentes. João Pessoa, PB: Gráfica JB, 2013. p. 133-153.

OLIVEIRA, P. S. Vidas compartilhadas: cultura e relações intergeracionais na vida cotidiana. 2. ed. São Paulo, SP: Cortez, 2011.

PÉCAULT, D. Os intelectuais e a política no Brasil. São Paulo, SP: Ática, 1990.

PERROT, M. Os excluídos da história: operários, mulheres, prisioneiros. 2. ed. Trad. Denise Bottmann. Rio de Janeiro, RJ: Paz e Terra, 1992.

PIMENTA, S. G. et al. Os cursos de licenciatura em pedagogia: fragilidades na formação inicial do professor polivalente. Educ. Pesq., São Paulo, v. 43, n. 1, p. 15-30, jan./mar. 2017. Disponível em: http://www.scielo.br/pdf/ep/v43n1/1517-9702-ep-43-1-0015.pdf. Acesso em: 13 maio 2019.

POLLAK, M. Memória e identidade social. Estudos Históricos, Rio de Janeiro, v. 5, n. 10, p. 200-212, 1992.

QUEIROGA, M. A. F. Dados biográficos. Documento manuscrito. 2016.

QUEIROGA, M. A. F. Caderno de anotações didáticas. Documento manuscrito, 1966.

QUEIROGA, M. A. F. Entrevista concedida a Iolanda de Sousa Barreto. Catolé do Rocha (PB), 1 out. 2016a.

QUEIROGA, M. A. F. Entrevista concedida a Iolanda de Sousa Barreto. Catolé do Rocha (PB), 30 nov. 2017.

QUEIROGA, M. A. F. Projeto Flor de Mandacaru. Documento manuscrito, 2005.

SENDRA, S. R. Irmãs Franciscanas de Dillingen: da expansão ao hoje de nossa história. Duque de Caxias: Província da Divina Providência no Brasil; Petrópolis: Sermograf, 2007. 
SOUSA, M. C. S. Colégio Normal Francisca Mendes: caminhos da escola normal em Catolé do Rocha/PB (1939-1959). Orientador: Carlos Augusto Amorim Cardoso. 2012. Dissertação (Mestrado em Educação) - Universidade Federal da Paraíba, João Pessoa, PB, 2012.

\section{Como referenciar este artigo}

BARRETO, I. S.; MACHADO, C. J. S.; NUNES, M. L. S. Narrativa de vida de Maria Fernandes de Queiroga (irmã Ana, OSF): memória, história e identidade docente. Revista Ibero-Americana de Estudos em Educação, Araraquara, v. 16, n. esp. 3, p. 1404-1421, jun. 2021. e-ISSN: 1982-5587. DOI: https://doi.org/10.21723/riaee.v16iesp.3.15289

Submissão em: 05/02/2021

Revisões requeridas em: 30/03/2021

Aprovado em: $12 / 05 / 2021$

Publicado em: 01/06/2021 